\title{
PRELIMINARY SURVEY OF GASTRO-INTESTINAL HELMINTH INFECTION IN HERBIVOROUS LIVESTOCK OF MOUNTAINOUS REGIONS OF BHUTAN AND ARUNACHAL PRADESH
}

\author{
V. Tandon ${ }^{1,3}$, P.K. Kar ${ }^{1}$, B. Das ${ }^{1}$, B. Sharma ${ }^{2}$ and J. Dorjee ${ }^{2}$ \\ 1 Department of Zoology, North-Eastern Hill University, Shillong, Meghalaya 793022, India \\ ${ }^{2}$ Regional Veterinary Laboratory, Khaling, Bhutan \\ Email: ${ }^{3}$ tandonveena@hotmail.com
}

\begin{abstract}
A coprological survey was made to assess the spectrum of helminth parasites in Mithun and other co-existing wild livestock in Bhutan and neighbouring Arunachal Pradesh (India). Nematodes with direct life cycle were found to be most predominant helminth infection among these animals. Cestodes and trematodes were poorly represented as their occurrence is primarily determined by the presence of the invertebrate intermediate hosts in the locality of the final host.
\end{abstract}

\section{KEYWORDS \\ Arunachal Pradesh, Bhutan, Gaur, Helminth parasite, Mithun, Siri cow}

The Mithun (Bos frontalis), an endangered and indigenous species of Indo-Burma region, is mostly found in the mountainous regions of northeastern India, Arunachal Pradesh in particular. This species has also spread to some parts of Myanmar and Bhutan either through government purchase or through direct farmer purchase. It has socio-economic, religious and cultural importance in the tribal society of the region. The animal prefers evergreen forests and can adapt well to altitudes ranging between 600 and $3000 \mathrm{~m}$. In the present study the helminth parasite spectrum of Mithun along with other herbivorous livestock such as Gaur and local siri cows was explored in selected localities of Bhutan and in neighbouring Arunachal Pradesh (India).

\section{Methods}

In Bhutan the survey areas included the Regional Mithun Breeding Farm (RMBF) at Aerong (2500m) where Mithuns and Gaurs (Bos gaurus) are kept, and Wamrong (2800m) where only the local Siri cows (Bos indicus) are reared and maintained on free-range basis. Faecal samples were collected from 50 Siri cows from Wamrong farm, and from 79 Mithuns and three Gaurs at RMBF. The collected samples were preserved in AFA (alcohol, formalin and acetic acid medium), brought to the laboratory and examined for parasitic infection as per Georgi's technique (1995). Some preserved adult specimens of parasites kept at the Khaling Satellite Laboratory at Deothang $(10 \mathrm{~km}$ down south from Aerong) were also examined for identification. In Arunachal Pradesh, coprological samples were collected from three wild mithuns at Along $(2200 \mathrm{~m})$ that were freshly slaughtered for some local ceremonial activity; the gut contents of the sacrificed animals were also examined.

\section{Results And Discussion}

The coprological survey revealed the occurrence of some helminth parasites among the Mithun, Gaur and Siri cows in Bhutan (Table 1). The parasites prevalent include Trichuris, Capillaria, Strongyloides, Toxocara, Ascaris, Oesophagostomum, Bunostomum, Mecistocirrus, Cooperia, Ostertagia and Thelazia representing the nematode group that included the larvae of Dictyocaulus (lung worm) also, and Moniezia and Anoplocephala from the cestode group; the trematodes included Fasciola and certain paramphistomids including Gastrodiscoides, Gastrothylax and Paramphistomum. While the nematode group emerged as the most predominant helminth infection with Strongyloides and Trichuris common to all the three host species, the cestode and trematode groups were conspicuous by their absence in Gaur. Further, while Fasciola and Moniezia were found to be prevalent in both Siri and Mithun (Table 1) in which taeniid eggs were also present, the Anoplocephala infection was restricted to Siri only and that of parampistomids, to Mithun. The adult specimens retrieved from the preserved stock at Deothang could be identified only up to generic level and included Trichuris, Dictyocaulus, Ascaris, Taenia, Fasciola, Gastrothylax, Gastrodiscoides and Paramphistomum.

From Along (Arunachal Pradesh), only adult Strongyloides sp. were recovered from the intestine of Mithun and the intensity of infection was high, with $\sim 150$ worms per infected host. In faecal examination, presence of Dictyocaulus (lungworm) infection was also revealed (Table 1).

The presence of helminth parasites in the herbivores can be explained in the light of their feeding habits. The ingestion of food contaminated with the parasitic eggs and third stage larvae $\left(\mathrm{L}_{3}\right)$ is a common mode of transmission of geohelminthic nematodes. Trichuris and Strongyloides spp. are reported to be present in zoo animals including cattle (Adkoli et al., 1986; Modi et al., 1995) and other mammals (Joseph et al., 1999; Rajendran et al., 2003). In the present study, these two infections were found among all the host species surveyed in Bhutan, though in Mithun from Along (Arunachal Pradesh) only Strongyloides and Dictyocaulus were found. A wider exploration with more samples is needed to assess the true status of helminthiasis in Mithun in Arunachal Pradesh, which has similar geo-climatic conditions as in Bhutan. Trichuris, Capillaria, Strongyloides, Ascaris, Oesophagostomum, Bunostomum and Mecistocirrus have been reported in the 
Table 1. Eggs of helminth parasites in faecal samples of cattle livestock in Bhutan and neighbouring Arunachal Pradesh

\begin{tabular}{|c|c|c|c|}
\hline Host: locality & Nematodes & Cestodes & Trematodes \\
\hline $\begin{array}{l}\text { Siri cows (Bos indicus): } \\
\text { Wamrong, Bhutan }\end{array}$ & $\begin{array}{l}\text { Trichuris, Strongyloides, Toxocara, Ascaris, } \\
\text { Oesophagostomum, Bunostomum, Mecistocirrus }\end{array}$ & $\begin{array}{l}\text { Anoplocephala, Moniezia, } \\
\text { Taeniid species }\end{array}$ & Fasciola \\
\hline $\begin{array}{l}\text { Mithun (B. frontalis): } \\
\text { Aerong, Bhutan }\end{array}$ & $\begin{array}{l}\text { Trichuris, Capillaria, Strongyloides, Toxocara, } \\
\text { Ascaris, Oesophagostomum, Bunostomum, } \\
\text { Mecistocirrus, Cooperia, Ostertagia, Thelazia, Dictyocaulus }\end{array}$ & Moniezia, Taeniid species & $\begin{array}{l}\text { Fasciola, Gastrodiscoides, } \\
\text { Gastrothylax, Paramphistomum }\end{array}$ \\
\hline Along, Arunachal Pradesh & Strongyloides, Dictyocaulus & - & - \\
\hline Gaur (B. gaurus): Aerong, Bhutan & Trichuris, Strongyloides & - & - \\
\hline
\end{tabular}

livestock in northeastern India, Meghalaya in particular (Yadav \& Tandon, 1988, 1989; Mahanta et al., 1996; Tandon, 2003) irrespective of the altitudinal differences of the various regions. Trichuris sp. is of common occurrence in captive wild herbivores including Mithun in the region (Chakraborty, 1992). Mecistocirrus adult nematodes have also been recovered from ruminant mammals in Sikkim Himalayas (Dr. Papri Dutta, ICAR Lab, Gangtok, pers. comm.). However, the cattle hosts in Bhutan were found to harbour Toxocara, Cooperia, Ostertagia and Thelazia, besides the afore-mentioned parasites. Toxocara is found in most parts of the world, whereas the species of Cooperia are mostly distributed in North America, Europe, Africa and Australian continents. The occurrence of Cooperia sp. has also been recorded earlier from captive herbivores in Assam, India (Chakraborty et al., 1994). Of Ostergia spp., mostly found in cattle, only one species, namely $O$. pinnata, has been reported in India from sheep. Thelazia spp., reported to inhabit the orbital cavity of a variety of mammals including cattle, horse, pig, rodents, dog etc. around the world, are also common parasites of cattle in India and neighbouring South Asian and Neareast countries (Soulsby, 1982). Anoplocephala occurs as a common parasite of horses and donkeys (Soulsby, 1982) and has also been reported from captive wild herbivores including rhinoceros (Chakraborty \& Islam, 1993). The occurrence of Anoplocephala in Siri cows and also of taeniid eggs in faecal samples from both Siri cows and Mithuns in Bhutan as reported in the present study seem to be stray or incidental cases, as there might be contamination by parasite eggs originating from faeces of horses and carnivorous animals like dogs or cats at the sample collection sites (grazing pastures). While the distribution of cestode infection in livestock is influenced by the occurrence of the invertebrate arthropod fauna that harbour the infective metacestode, that of trematodes is affected by the presence/absence of the snail intermediate hosts in the vicinity. The poor representation or no occurrence of trematodes can be attributed to the fact that gastropod molluscs that form an important link in the life cycle of majority of them do not have a rich faunal diversity or do not prevail in the hostile environmental conditions at the higher altitudinal areas.

\section{REFERENCES}

Adkoli, N.S., C.K. Mondal and J.N. Ghose (1986). Parasitic infection in zoo animals. Zoo Zen 2(3): 22-26.

Chakraborty, A. (1992). Trichuris sp. infection in wild captive herbivores. Journal of Veterinary Parasitology 6(2): 37-40.

Chakraborty, A., and S. Islam (1993). A survey of gastrointestinal parasitic infection in free-living rhinoceros of the Kaziranga National Park. Indian Journal of Animal Sciences 63(2): 155-156.
Chakraborty, A., A.R. Gogoi and B. Chaudhury (1994). Prevalence of parasitic infection in captive wild herbivores in a zoo in Assam, India. International Journal of Animal Sciences 9(2): 149-152.

Georgi, J.R. (1995). Parasitology for Veterinarians. $4^{\text {th }}$ edition. W.B. Saunders, London, 344pp.

Joseph, G.K., K.M. Pillai, F. Xavier, B. Michael and M. Amrithraj (1999). A coprological study of parasites in two endangered primates of Silent Valley National Park, Kerala. Indian Forester 125(10): 10271030 .

Mahanta, J., J. Alger and P. Bordoloi (1996). Eye infection with Thelazia species. Indian Journal of Ophthalmology 44: 99-100.

Modi, G.S., B.N. Prasad, A.K. Sinha and B.K. Sinha (1995). Parasitic infections in herbivorous zoo animals. Indian Journal of Veterinary Research 4(2): 45-50.

Rajendran, S., P.C. Saseendran, H. Subramanian, R. Chitra and N. Yuvaraj (2003). A survey of gastro-intestinal parasitic infection in Nilgiri Langur (Semnopithecus johnii) at Kalakkad-Mundanthurai Tiger Reserve, Tamil Nadu. Zoos' Print Journal 19(4): 1454.

Soulsby, E.J.L. (1982). Helminths, Arthopodes and Protozoa of Domestic animals, pp. 808-815. Lea and Febiger, Philadelphia.

Tandon, V. (2003). Spectrum of Helminth parasites in North-East India, pp. 57-76. In: Sood, M.L. (Ed.). Helminthology in India. International Book Distributors, India.

Yadav, A.K. and V. Tandon (1988). Nematode fauna of livestock and poultry of Meghalaya. Indian Journal of Helminthology 5(2): 29-45.

Yadav, A.K. and V. Tandon (1989). Gastointestinal nematode infections of goats in a sub-tropical and humid zone of India. Veterinary Parasitology 28: $169-171$.

\section{ACKNOWLEDGEMENTS}

This study was supported by the AICOPTAX programme of the Ministry of Environment and Forests, GOI, sanctioned to VT at NEHU. We are grateful to the Royal Government of Bhutan for the permission to survey the livestock in their country and to the Director, Department of Livestock, Ministry of Agriculture, Bhutan, for his technical and administrative support for this study. Cooperation and support of the farm management of NNBF, Tashiyangphu, and RMBF, Aerong, is gratefully acknowledged.

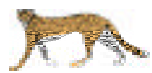

